\title{
Accelerated hypofractionated three- dimensional conformal radiation therapy (3 Gy/fraction) combined with concurrent chemotherapy for patients with unresectable stage III non-small cell lung cancer: preliminary results of an early terminated phase II trial
}

Xiao-Cang Ren'1, Quan-Yu Wang ${ }^{1}$, Rui Zhang ${ }^{1}$, Xue-Ji Chen ${ }^{1}$, Na Wang ${ }^{1}$, Yue-E Liu' ${ }^{1}$ Jie Zong ${ }^{1}$, Zhi-Jun Guo², Dong-Ying Wang ${ }^{3}$ and Qiang Lin ${ }^{1^{*}}$

\begin{abstract}
Background: Increasing the biological effective dose (BED) of radiotherapy for non-small cell lung cancer (NSCLC) can increase local control rates and improve overall survival. Compared with conventional fractionated radiotherapy, accelerated hypofractionated radiotherapy can yield higher BED, shorten the total treatment time, and theoretically obtain better efficacy. However, currently, there is no optimal hypofractionated radiotherapy regimen. Based on phase I trial results, we performed this phase II trial to further evaluate the safety and preliminary efficacy of accelerated hypofractionated three-dimensional conformal radiation therapy(3-DCRT) combined with concurrent chemotherapy for patients with unresectable stage III NSCLC.

Methods: Patients with previously untreated unresectable stage III NSCLC received 3-DCRT with a total dose of 69 Gy, delivered at 3 Gy per fraction, once daily, five fractions per week, completed within 4.6 weeks. At the same time, platinum doublet chemotherapy was applied.

Results: After 12 patients were enrolled in the group, the trial was terminated early. There were five cases of grade III radiation esophagitis, of which four cases completed the radiation doses of 51 Gy, 51 Gy, 54 Gy, and 66 Gy, and one case had 16 days of radiation interruption. The incidence of grade III acute esophagitis in patients receiving an irradiation dose per fraction $\geq 2.7$ Gy on the esophagus was $83.3 \%(5 / 6)$. The incidence of symptomatic grade III radiation pneumonitis among the seven patients who completed 69 Gy according to the plan was $28.6 \%$ (2/7). The median local control (LC) and overall survival (OS) were not achieved; the 1-year LC rate was $59.3 \%$, and the 1-year OS rate was $78.6 \%$.

(Continued on next page)
\end{abstract}

\footnotetext{
* Correspondence: billhappy001@163.com

'Department of Oncology, North China Petroleum Bureau General Hospital of Hebei Medical University, 8 Huizhan Avenue, Renqiu City, Hebei Province 062552, P.R. China

Full list of author information is available at the end of the article
} 
(Continued from previous page)

Conclusion: For unresectable stage III NSCLC, the accelerated hypofractionated radiotherapy with a total dose of 69 Gy ( $3 \mathrm{~Gy} / \mathrm{f}$ ) combined with concurrent chemotherapy might result in severe radiation esophagitis and pneumonitis to severely affect the completion of the radiotherapy. Therefore, we considered that this regimen was infeasible. During the hypofractionated radiotherapy with concurrent chemotherapy, the irradiation dose per fraction to esophagus should be lower than $2.7 \mathrm{~Gy}$. Further studies should be performed using esophageal tolerance as a metric in dose escalation protocols.

Trial registration: NCT02720614, the date of registration: March 23, 2016.

Keywords: Non-small cell lung cancer, Accelerated hypofractionated radiotherapy, Three-dimensional conformal radiation therapy, Concurrent radiochemotherapy, Maximum tolerated dose

\section{Background}

According to the 2008 global cancer statistics, the morbidity and mortality of lung cancer ranks first worldwide [1]. China also faces a similar situation. According to the 2010 data released by the National Cancer Control Office of the National Cancer Center, the new cases of lung cancer every year totaled approximately 600,000 , and the cases of death number approximately 490,000 [2]. For unresectable locally advanced non-small cell lung cancer (NSCLC), concurrent radiochemotherapy is the standard treatment $[3,4]$. The classical concurrent radiochemotherapy program uses conventional fractionated radiation with a total dose of 60-66 Gy; however, the local recurrence rate is still as high as $30 \%$ [4]. Studies have suggested that increasing the tumor radiation dose could increase the local control, thus improving survival $[5,6]$. However, the RTOG06-17 study using the conventional fractionated regimen showed that, compared with the 60-Gy group, the survival was not increased in the 74-Gy high-dose group [7]. Although the exact reasons were not clear, the very long treatment time (7.4 weeks) in the high-dose group might be one of the reasons [3].

Studies in head and neck squamous cell carcinoma have shown that tumor cells start to accelerate repopulation after 4 weeks of radiotherapy; at this time, the doubling time of tumor cells shortened from 60 days without interference to 4 days. To eliminate this re-proliferation, an extra 0.6-Gy dose was required each day for compensation [8]. This result also partially explained the possible reasons behind the poor effect of conventional fractionated radiotherapy. For NSCLC radiotherapy, after 4 weeks, when the treatment time was increased by 1 day, a 0.45 -Gy radiation dose was lost. Therefore, extension of the total treatment time might be a key reason causing the failure of local control [9]. The continuous, hyperfractionated, accelerated radiotherapy (CHART) program continued giving hyperfractionated radiation for 12 days; although the total dose was only $54 \mathrm{~Gy}$, the absolute value of the 2-year survival increases by $9 \%$ compared with the conventional fractionation of 60 Gy (2 Gy/fraction) (29 \% vs $20 \%$, respectively) [10]. Hypofractionated radiotherapy has a dosimetric advantage; it shortens the treatment time, increases the biological effective dose (BED), and can potentially reduce the effect of accelerated repopulation on local failure $[6,11]$. Compared with hyperfractionated radiation, hypofractionated radiotherapy has the advantages of convenience, economy, and easy implementation; thus, it has increasingly more clinical applications [12-29].

It has been confirmed that combined radiochemotherapy is better than radiotherapy alone [30], conventional fractionated radiotherapy with concurrent chemotherapy is better than sequential radiotherapy and chemotherapy, and the overall survival (OS) shows benefits with a $5.7 \%$ 3 -year OS and a $4.5 \%$ 5-year OS [4]. Similarly, hypofractionated radiotherapy combined with concurrent chemotherapy can also theoretically further increase the efficacy. Experimental research has shown that hypofractionated radiotherapy with concurrent chemotherapy could increase the efficacy [31]. However, due to the concern about the aggressive toxicity of hypofractionated radiotherapy with concurrent chemotherapy, this type of clinical research is relatively rare. The applied fractionated dose and chemotherapy regimens have larger differences, and the optimal program of hypofractionated radiotherapy with concurrent chemotherapy has not been confirmed. We previously conducted a phase I study of hypofractionated radiotherapy (3 Gy/fraction) with concurrent chemotherapy and considered that NSCLC could tolerate the high 69-Gy dose [32]. Base on this finding, we performed the current phase II study to further evaluate the safety and preliminary efficacy of 69-Gy/23-fraction (3 Gy/ fraction) hypofractionated radiotherapy with concurrent radiochemotherapy. Only 12 cases were enrolled in this study. Because of the strong esophagus and lung toxicity, this trial was prematurely terminated. The detailed results are reported below.

\section{Methods}

Inclusion criteria

Patients with previously untreated unresectable stage IIIA or stage IIIB NSCLC (as defined by the 2009 staging standards of the International Union Against Cancer 
(UICC)) were recruited, who were confirmed pathologically or cytologically. The age range was between 18 and 75 years, the Karnofsky performance status (KPS) score was $\geq 70$, and the expected survival time was $\geq 3$ months. The laboratory examination results showed a neutrophil count $\geq 2.0 \times 10^{9}$, a hemoglobin level $\geq 100 \mathrm{~g} / \mathrm{L}$, a platelet count $\geq 100 \times 10^{9}$, and the values of serum creatinine, alanine aminotransferase, aspartate aminotransferase, and total bilirubin were lower than the upper limit of the normal values. The patients did not show abnormal electrocardiogram (ECG) results. Additionally, they did not have other combined diseases that required hospitalization.

\section{Exclusion criteria}

Patients who were pregnant, breastfeeding, had another malignant tumor history (with the exception of patients with cervical carcinoma in situ and non-malignant melanoma skin cancer that had been clinically cured for at least 5 years), could not receive concurrent chemotherapy due to medical reasons, and had superior vena cava syndrome and severe lung diseases that affected lung function were excluded.

This clinical trial was approved by the Ethics Committee of the North China Petroleum Bureau General Hospital of Hebei Medical University. This trial was performed in accordance with the principles of human clinical trials and the Helsinki Declaration (1975 edition and 2000 revised edition). All of the patients signed informed consent before enrollment.

\section{Patient assessment}

Patient assessment was performed within 2 weeks before the start of treatment. The items included a complete medical history, comprehensive physical examination, thoracic, abdominal and head enhanced computed tomography $(\mathrm{CT})$ or head magnetic resonance imaging (MRI), ECG, bronchoscopy, whole-body bone scanning using emission CT (ECT) as suggested by clinical, routine blood tests, and full blood biochemical items.

Patients received a physical examination and routine blood tests every week (if necessary, the frequency could be increased). The full blood biochemical tests and ECG were re-examined before each chemotherapy treatment.

\section{Research design}

This phase II clinical trial was an open-label, single-arm, and safety study. The primary endpoint was the toxicity of the accelerated hypofractionated three-dimensional conformal radiation therapy (69 Gy, $3 \mathrm{~Gy} /$ fraction) with concurrent chemotherapy program. The secondary research endpoint included progression-free survival (PFS), median survival time (MST), OS, and local control (LC). A sample size of 30 evaluable patients was determined arbitrarily, if the toxicity induced by the regimen could be tolerated [33].

\section{Radiotherapy}

The three-dimensional conformal technology with accelerated hypofractionated radiotherapy was completed within 4.6 weeks, with a total dose of 69 Gy, delivered at 3 Gy per fraction, once daily, five fractions per week. The chemoradiotherapy treatment scheme is depicted in Table 1.

The specific radiotherapy program has been described in detail in the phase I trial [32]. The limitation conditions of irradiation on important organs were as follows: V $20 \leq 30 \%$, spinal cord $0 \%>40$ Gy, and $\leq 12 \mathrm{~cm}$ esophagus within PTV [24, 27]. Limitation of irradiation to the esophagus was not mandatory, and could be appropriately broadened for the better PTV irradiation.

\section{Chemotherapy}

Chemotherapy was conducted concurrently with radiotherapy. Chemotherapy regimen 1 was as follows: vinorelbine (NVB) was administered by intravenous infusion at a dose of $25 \mathrm{mg} / \mathrm{m}^{2}$ on day 1 (d1) and day 8 (d8), and carboplatin (CBP) was administered at a concentrationtime curve (AUC) of $5 \mathrm{mg} / \mathrm{ml}$ on $\mathrm{d} 8$. This treatment was repeated every 28 days. One cycle of chemotherapy was performed concurrently with the radiotherapy. Chemotherapy regimen 2 was as follows: paclitaxel at $30 \mathrm{mg} / \mathrm{m}^{2}$ and cisplatin at $20 \mathrm{mg} / \mathrm{m}^{2}$ (TP) were administrated every week for 5 weeks continuously.

Table 1 Concurrent chemoradiotherapy schema

\begin{tabular}{|c|c|c|c|c|c|c|}
\hline \multicolumn{7}{|c|}{ Concurrent chemoradiotherapy schema } \\
\hline \multicolumn{7}{|c|}{ RT regimen: Weeks 1-5: 3 Gy/f, 1 f/d,5 f/w; } \\
\hline Week & 1 & 2 & 3 & 4 & 5 & \\
\hline RT & I I I I I & I I I I I & I I I I I & I I I I I & I I I & \\
\hline \multicolumn{7}{|c|}{ Chemotherapy for Patient1-6: NVB (25 mg/m2) d1, d8; CBP,AUC = 5 mg/m1.min on d8, repeated every 28 days } \\
\hline NVB & $\diamond$ & $\diamond$ & & & $\diamond$ & $\diamond$ \\
\hline CBP & & $\bullet$ & & & & $\bullet$ \\
\hline \multicolumn{7}{|c|}{ Chemotherapy for Patient7-12: Paclitaxel(T): 30 mg/m2,Cisplatin(P) 20 mg/m2,weekly,w1-w5. } \\
\hline TP & $\boldsymbol{\Delta}$ & $\boldsymbol{\Delta}$ & $\boldsymbol{\Delta}$ & $\boldsymbol{\Delta}$ & $\boldsymbol{\Delta}$ & \\
\hline
\end{tabular}


After radiotherapy was finished, consolidation of chemotherapy using the original regimen was conducted for a maximum of four cycles.

\section{Supportive care and dose adjustment}

The regimen of supportive care and dose adjustment is described in detail in the phase I trial [32].

\section{Evaluation of short-term efficacy and toxicity}

Four weeks after the completion of radiotherapy, the short-term efficacy was evaluated using the thoracicabdominal spiral CT based on the Response Evaluation Criteria in Solid Tumors, version 1.1, (RECIST 1.1) standard [34]. The Common Terminology Criteria for Adverse Events (CTCAE), version 3.0 issued by the National Cancer Institute/National Institutes of Health $(\mathrm{NCI} / \mathrm{NIH})$ was used as the standard for toxicity evaluation [35]. Evaluation was performed each week during the radiotherapy. Adverse events that occurred more than 90 days after the beginning of radiotherapy were classified as late toxicity.

\section{Follow-up and statistics}

A follow-up was conducted every 2 months for the first 6 months after the completion of radiotherapy, every 3 months between 6 months and 2 years, and every 6 months thereafter. All of the statistical analyses were performed using the SPSS 19.0 biostatistical software package or the R3.2.2 statistical software package. The $95 \%$ confidence interval was calculated using the exact binomial test. Regression analysis was performed using logistic regression. The correlation analysis of esophagitis was performed using Spearman's testing [22]. The survival data were evaluated using the Kaplan-Meier method. The survival time was measured from the initiation of the concurrent radiochemotherapy until death due to any cause or the last follow-up event. Only the first treatment failure was considered as the reason for failure. PFS was defined as survival without local recurrence or distant metastases.

\section{Results}

\section{Patient condition}

From April 2013 to July 2014, 12 patients with previously untreated NSCLC confirmed by pathology and cytology were enrolled in this study; all 12 cases received toxicity and efficacy evaluations. The clinical information of patients is shown in Table 2. The median age was 65 years, and the median KPS score was 80 . There were nine cases of squamous carcinoma, two cases of adenocarcinoma and one case of undifferentiated carcinoma. There were four cases with stage IIIA and eight cases with stage IIIB disease. The details of the clinical staging are shown in Table 3. The median gross tumor volume (GTV) was $55.7 \mathrm{~cm}^{3}$ (mean, $65.3 \mathrm{~cm}^{3}$; range, $7.9-178.0 \mathrm{~cm}^{3}$ ), and the
Table 2 Patient characteristics

\begin{tabular}{|c|c|c|c|}
\hline \multirow[t]{2}{*}{ Characteristic } & \multicolumn{2}{|l|}{ No. of patients } & \multirow{2}{*}{$\begin{array}{l}\text { Percentage of } \\
\text { Patients (\%) }\end{array}$} \\
\hline & $N=12$ & & \\
\hline \multicolumn{4}{|l|}{ Gender } \\
\hline Male & 11 & & 91.7 \\
\hline Female & 1 & & 8.3 \\
\hline \multicolumn{4}{|l|}{ Age } \\
\hline Median & & 65 & \\
\hline Range & & $45-75$ & \\
\hline \multicolumn{4}{|l|}{ Karnofsky performance status } \\
\hline Median & & 80 & \\
\hline Range & & $70-90$ & \\
\hline \multicolumn{4}{|l|}{ Histology } \\
\hline Squamous cell carcinoma & 9 & & 75.0 \\
\hline Adenocarcinoma & 2 & & 16.7 \\
\hline Undifferentiated carcinoma & 1 & & 8.3 \\
\hline \multicolumn{4}{|l|}{ Stage } \\
\hline$\| \mathrm{A}$ & 4 & & 33.3 \\
\hline$\| I \mathrm{~B}$ & 8 & & 66.7 \\
\hline
\end{tabular}

median planning target volume (PTV) was $261.0 \mathrm{~cm}^{3}$ (mean, $263.3 \mathrm{~cm}^{3}$; $130.3-415.7 \mathrm{~cm}^{3}$ ).

\section{Compliance}

Seven among the 12 cases completed the 69-Gy radiation according to the treatment protocol. Five cases did not complete the protocol due to severe radiation esophagitis, one case suspended the radiotherapy for 16 days (suspension of radiation for more 14 days was considered a major violation of the treatment plan), and the other four cases completed 51 Gy, 51 Gy, 54 Gy, and 66 Gy of radiation. The $95 \%$ unilateral confidence interval of grade III and above esophagitis was $\geq 18.26 \%$. The incidence of severe esophagitis (grade III and above) in lung cancer

Table 3 Detailed staging for patients with NSCLC

\begin{tabular}{|c|c|c|c|c|}
\hline NO. & Location & Stage & TNM & Nodal staging \\
\hline$\overline{1}$ & Right upper & IIIA & T2aN2M0 & $4 \mathrm{R}, 4 \mathrm{~L}, 10$ \\
\hline 2 & Right upper & IIIA & T3N2M0 & $2 \mathrm{R}, 4 \mathrm{R}$ \\
\hline 3 & Left lower & $\| \mathrm{A}$ & T4N0MO & None \\
\hline 4 & Left lower & IIIB & $\mathrm{T} 1 \mathrm{bN} 3 \mathrm{M} 0$ & $4 \mathrm{R}, 4 \mathrm{~L}$ \\
\hline 5 & Right upper & $\| I \mid B$ & $\mathrm{~T} 4 \mathrm{~N} 3 \mathrm{M} 0$ & $1 R, 2 R, 4 R, 4 L, 5,7,8,10$ \\
\hline 6 & Right upper & $\| \mathrm{II}$ & T4N3M0 & $4 \mathrm{R}, 4 \mathrm{~L}, 5,10$ \\
\hline 7 & Right upper & IIIB & $\mathrm{T} 2 \mathrm{aN} 3 \mathrm{MO}$ & $4 \mathrm{R}, 10$, supraclavicular \\
\hline 8 & Right middle & $\| \mathrm{A}$ & $\mathrm{T} 3 \mathrm{~N} 2 \mathrm{MO}$ & $1,2 \mathrm{R}, 3 \mathrm{~A}, 4 \mathrm{R}, 6$ \\
\hline 9 & Right lower & IIIB & $\mathrm{T} 4 \mathrm{~N} 2 \mathrm{MO}$ & $2 \mathrm{R}, 4 \mathrm{R}, 5,7$ \\
\hline 10 & Right upper & $\| \mathrm{II}$ & $\mathrm{T} 4 \mathrm{~N} 3 \mathrm{M} 0$ & $4 \mathrm{R}, 4 \mathrm{~L}, 7,10$ \\
\hline 11 & Right upper & IIIB & $\mathrm{T} 4 \mathrm{~N} 2 \mathrm{M} 0$ & $2 R, 4 R, 7,10$ \\
\hline 12 & Right upper & $\| I \mid B$ & T4N3M0 & $1 R, 2 R, 3 P, 4 R, 5,7$ \\
\hline
\end{tabular}


radiotherapy does not have recognized standards [36], especially for hypofractionated concurrent radiochemotherapy [22]. We referenced the mean value, $15 \%$ (6-24 \%), reported in literature, which was used as the standard [36]. After hypothesis testing, the results showed a significant difference $(p=0.02392)$. Therefore, we consider the incidence of severe esophagitis in our phase II trial higher than that in general studies. In addition, severe esophagitis significantly affected the completion of radiotherapy, and this radiotherapy regimen was not easy to implement in clinical practice. Therefore, this trial was terminated early after only 12 patients were enrolled in the study. All of the patients who received $\mathrm{NC}$ treatment completed 1 cycle of concurrent chemotherapy. Six patients who received weekly TP treatment completed 5, 4, 3, 3, 3, and 3 times of weekly concurrent chemotherapy.

\section{Non-hematological toxicity}

The detailed non-hematological toxicities are shown in Table 4. Five patients had acute grade III radiation esophagitis; which occurred at $30 \mathrm{~Gy} / 10$ fractions (No. 5), 36 Gy/12 fractions (No. 9), 45 Gy/15 fractions (No. 10), 39 Gy/13fractions (No. 11), and 45 Gy/15 fractions (No. 12). They were all given supportive measures such as intravenous infusion, antacid, and protection of esophagus and gastric mucosa. Patient No. 5 had severe esophageal pain at $45 \mathrm{~Gy} / 15$ fractions; due to the poor effect of narcotic analgesics, the patient could not tolerate and gave up the radiotherapy for a total of 16 days; the patient resumed the radiotherapy after esophagitis was reduced to grade II and finally completed $69 \mathrm{~Gy} / 23$ fractions. The other four patients who had grade II radiation esophagitis continued for 7-10 days; although they did not interrupt radiotherapy, they all did not finish the protocol and finally completed 51 Gy, 54 Gy, 51 Gy, and 66 Gy of radiotherapy, respectively.

After the radiotherapy was completed, the radiation esophagitis of patient No. 5, 9, and 11 recovered rapidly, and significant late-stage reaction was not observed (the follow-up time was 3, 6, and 5, respectively; at the 3month follow-up time, patient No.5 had already died). Patient No.10 had grade I esophagitis at the completion of radiotherapy; the patient had complete remission after the disease was persistent for 2 months and could resume normal eating (the follow-up time was 3 months). Patient No.12 already had dysphagia before admission and had semi-liquid food before radiotherapy. Esophageal imaging showed extrinsic compression changes and local stenosis. After radiotherapy, the dysphagia was partially relieved but was further aggravated after 3 months of radiotherapy than before radiotherapy. It was evaluated as a late esophageal toxicity of grade II. The disease was further aggravated after 6 months, and the patient could only take liquid food. Esophageal dilation therapy or gastrostomy was required (refused by the patient); thus, it was evaluated as a late esophageal toxicity of grade III. However, the disease evaluation showed that the local control and distant metastasis were relieved (the follow-time was 9 months).

We attempted to analyze factors associated with severe radiation esophagitis. Because of the limitations of the small sample size, only the two most likely associated factors relevant to clinical practice could be analyzed: metastasis of the seventh lymph node (mStation 7) and PTV volume. The results showed that neither mStation 7 nor PTV volume were significantly correlated with severe esophagitis; the $\mathrm{z}$ values were 0.001 and 0.000 , respectively, and the $p$ values were 1.000 and 1.000 ,

Table 4 Non-hematologic toxicity

\begin{tabular}{|c|c|c|c|c|c|c|c|c|c|c|}
\hline \multirow[t]{2}{*}{ Item } & \multicolumn{2}{|c|}{ Grade I } & \multicolumn{2}{|c|}{ Grade II } & \multicolumn{2}{|c|}{ Grade III } & \multicolumn{2}{|c|}{ Grade IV } & \multicolumn{2}{|l|}{ Total } \\
\hline & Case & $\%$ & Case & $\%$ & Case & $\%$ & Case & $\overline{\%}$ & Case & $\%$ \\
\hline \multicolumn{11}{|l|}{ Acute } \\
\hline Radiation esophagitis & 2 & 16.7 & 2 & 16.7 & 5 & 41.7 & 0 & 0 & 9 & 75.0 \\
\hline Radiation pneumonia & 2 & 16.7 & 1 & 8.3 & 2 & 16.7 & 0 & 0 & 5 & 41.7 \\
\hline Radiation dermatitis & 7 & 58.3 & 0 & 0 & 0 & 0 & 0 & 0 & 7 & 58.3 \\
\hline Nausea & 3 & 25.0 & 5 & 41.7 & 2 & 16.7 & 0 & 0 & 10 & 83.3 \\
\hline Vomiting & 4 & 33.3 & 2 & 16.7 & 0 & 0 & 0 & 0 & 6 & 50.0 \\
\hline Anorexia & 2 & 16.7 & 4 & 33.3 & 2 & 16.7 & 0 & 0 & 8 & 66.7 \\
\hline Fatigue & 4 & 33.3 & 2 & 16.7 & 1 & 8.3 & 0 & 0 & 7 & 58.3 \\
\hline ALT/ AST & 2 & 16.7 & 0 & 0 & 0 & 0 & 0 & 0 & 2 & 16.7 \\
\hline BIL & 3 & 25.0 & 1 & 8.3 & 0 & 0 & 0 & 0 & 4 & 33.3 \\
\hline \multicolumn{11}{|l|}{ Late } \\
\hline Lung & 2 & 16.7 & 2 & 16.7 & 1 & 8.3 & 0 & 0 & 5 & 41.7 \\
\hline Esophagus & 0 & 0 & 0 & 0 & 1 & 8.3 & 0 & 0 & 1 & 8.3 \\
\hline
\end{tabular}

ALT alanine aminotransferase, AST aspartate aminotransferase, BIL bilirubin 
respectively. Nevertheless, we observed that five patients with grade III radiation esophagitis all showed mStation 7 , while the seven patients who did not exhibit grade III and above esophagitis did not show mStation 7 . The Station 7 is adjacent to the esophagus. Lymph node metastasis in this region is easy to induce with a high dose of radiation in the esophagus, thus causing severe esophagitis. Although the regression analysis results did not show remarkable significance, we still propose that mStation 7 might be a risk factor for severe esophagitis. The final conclusion requires confirmation in future studies using large sample sizes.

Among the seven cases that completed the 69 Gy according to the treatment plan, three cases had symptomatic pneumonitis (grade II + III); however, among the five cases for which the protocol was not completed, there was no pneumonitis. The comparison between these two showed a significant difference $\left(\chi^{2}=3.935, P=0.047\right)$.

Nausea, fatigue, and loss of appetite were observed in most patients. However, these digestive tract symptoms were mild and were successfully alleviated through the administration of appropriate antiemetics and intravenous rehydration without affecting the implementation of chemoradiotherapy. Liver and kidney toxicities were rare. The detailed non-hematological toxicities are shown in Table 4.

\section{Radiation dose on the esophagus}

The detailed information of the radiation of the esophagus is shown in Tables 5, 6 and 7. The mean dose was from 263 Gy to $4,282 \mathrm{~Gy}$, and the maximum dose was from 2,832 Gy to 7,222 Gy. The dose volume parameters are shown in Table 5. The percentage of the esophageal volume that received a 5 Gy or greater radiation dose (V5) was set as the starting point. The dose increments of 5 Gy was used until V69 (the percentage of the esophageal volume that received a 69 Gy or greater radiation dose); a total of 14 dosimetric-volumetric parameters ranging from V5 to V69 were defined. The irradiation dose per fraction parameters are shown in Table 6. The Spearman's testing results showed that grade III acute esophagitis had a significant positive correlation with the irradiation dose per fraction to the esophagus, the total of 14 dose-volume parameters (V5-V69), maximum radiation dose, and mean radiation dose $(P<0.05)$.

\section{Hematological toxicity}

Neutropenia occurred in $58.3 \%$ (7/12) of patients; the overall disease was milder, and only one case had agranulocytosis $(8.3 \%)$. The percentage of the decrease of platelets and hemoglobin was low, and grade II and above disease did not occur. The hematological toxicity of weekly TP treatment was significantly milder than that in NC chemotherapy; the percentages of neutropenia were $16.7 \%$ and $100 \%$, respectively. The detailed hematological toxicities are shown in Table 8.

\section{Short-term treatment efficacy}

Evaluation of the short-term treatment efficacy was performed on 12 cases. The results showed that the complete response $(\mathrm{CR})$ was $0 \%(0 / 12)$, the partial response (PR) was $61.5 \%(11 / 12)$, and the stable disease (SD) was

Table 5 Irradiation dose to esophagus: ${ }^{a}$ Dose-volume

\begin{tabular}{|c|c|c|c|c|c|c|c|c|c|c|c|c|c|c|}
\hline NO. & $\begin{array}{l}\text { V5 } \\
(\%)\end{array}$ & $\begin{array}{l}\text { V10 } \\
(\%)\end{array}$ & $\begin{array}{l}\text { V15 } \\
\text { (\%) }\end{array}$ & $\begin{array}{l}\text { V20 } \\
(\%)\end{array}$ & $\begin{array}{c}\text { V25 } \\
(\%)\end{array}$ & $\begin{array}{l}\text { V30 } \\
(\%)\end{array}$ & $\begin{array}{l}\text { V35 } \\
\text { (\%) }\end{array}$ & $\begin{array}{l}\text { V40 } \\
(\%)\end{array}$ & $\begin{array}{c}\text { V45 } \\
(\%)\end{array}$ & $\begin{array}{l}\text { V50 } \\
\text { (\%) }\end{array}$ & $\begin{array}{l}\text { V55 } \\
\text { (\%) }\end{array}$ & $\begin{array}{l}\text { V60 } \\
(\%)\end{array}$ & $\begin{array}{c}\text { V65 } \\
(\%)\end{array}$ & $\begin{array}{l}\text { V69 } \\
(\%)\end{array}$ \\
\hline 1 & 9.93 & 1.31 & 0.52 & 0 & 0 & 0 & 0 & 0 & 0 & 0 & 0 & 0 & 0 & 0 \\
\hline 2 & 39.71 & 29.79 & 28.22 & 25.34 & 18.29 & 14.63 & 12.28 & 11.76 & 9.93 & 7.05 & 3.14 & 0 & 0 & 0 \\
\hline 3 & 31.35 & 31.35 & 31.35 & 31.35 & 30.31 & 30.31 & 30.31 & 30.31 & 30.31 & 30.31 & 29 & 25.87 & 19.60 & 0.78 \\
\hline 4 & 41.54 & 38.67 & 38.67 & 38.67 & 24.82 & 0 & 0 & 0 & 0 & 0 & 0 & 0 & 0 & 0 \\
\hline 5 & 65.32 & 62.97 & 60.36 & 58.00 & 58.00 & 58.00 & 57.74 & 57.22 & 56.70 & 55.39 & 50.95 & 49.90 & 41.81 & 6.01 \\
\hline 6 & 37.10 & 30.05 & 27.96 & 24.56 & 24.04 & 23.52 & 19.33 & 9.93 & 3.66 & 2.87 & 0 & 0 & 0 & 0 \\
\hline 7 & 30.31 & 30.31 & 29.52 & 19.07 & 4.96 & 2.87 & 2.61 & 1.57 & 0 & 0 & 0 & 0 & 0 & 0 \\
\hline 8 & 65.06 & 56.70 & 53.82 & 49.38 & 45.20 & 33.97 & 32.66 & 25.61 & 4.96 & 0.52 & 0 & 0 & 0 & 0 \\
\hline 9 & 44.94 & 41.54 & 41.02 & 40.76 & 36.58 & 30.57 & 20.08 & 19.33 & 19.07 & 18.29 & 17.51 & 16.72 & 15.42 & 2.35 \\
\hline 10 & 54.09 & 48.86 & 45.99 & 45.46 & 43.11 & 42.85 & 37.89 & 37.89 & 34.44 & 34.23 & 32.40 & 28.74 & 17.24 & 0 \\
\hline 11 & 40.12 & 38.93 & 38.64 & 36.84 & 35.80 & 33.97 & 32.40 & 31.62 & 29.52 & 28.48 & 28.22 & 26.39 & 26.13 & 20.12 \\
\hline 12 & 70.02 & 66.63 & 65.84 & 64.54 & 64.28 & 64.28 & 64.01 & 63.75 & 61.62 & 61.40 & 58.27 & 53.82 & 47.03 & 18.81 \\
\hline$p$ & 0.019 & 0.010 & 0.019 & 0.019 & 0.010 & 0.002 & 0.009 & 0.004 & 0.004 & 0.004 & 0.002 & 0.000 & 0.001 & 0.006 \\
\hline$r^{b}$ & 0.661 & 0.710 & 0.661 & 0.661 & 0.710 & 0.786 & 0.711 & 0.760 & 0.764 & 0.764 & 0.787 & 0.862 & 0.810 & 0.737 \\
\hline
\end{tabular}

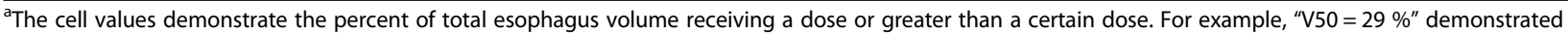
that the esophagus volume received 50Gy or more was $29 \%$

' $" r$ " refers to the correlation coefficient calculated by Spearman's testing 
Table 6 Irradiation dose to esophagus: ${ }^{a}$ Dose per fractionation

\begin{tabular}{|c|c|c|c|c|c|c|c|c|c|c|}
\hline NO. & $\begin{array}{l}2 \mathrm{~Gy} \\
\mathrm{~cm}\end{array}$ & $\begin{array}{l}2.2 \mathrm{~Gy} \\
\mathrm{~cm}\end{array}$ & $\begin{array}{l}2.4 \mathrm{~Gy} \\
\mathrm{~cm}\end{array}$ & $\begin{array}{l}2.6 \mathrm{~Gy} \\
\mathrm{~cm}\end{array}$ & $\begin{array}{l}2.7 \mathrm{~Gy} \\
\mathrm{~cm}\end{array}$ & $\begin{array}{l}2.8 \mathrm{~Gy} \\
\mathrm{~cm}\end{array}$ & $\begin{array}{l}2.85 \text { Gy } \\
\mathrm{cm}\end{array}$ & $\begin{array}{l}2.9 \mathrm{~Gy} \\
\mathrm{~cm}\end{array}$ & $\begin{array}{l}2.95 \mathrm{~Gy} \\
\mathrm{~cm}\end{array}$ & $\begin{array}{l}3 \mathrm{~Gy} \\
\mathrm{~cm}\end{array}$ \\
\hline 1 & 0 & 0 & 0 & 0 & 0 & 0 & 0 & 0 & 0 & 0 \\
\hline 2 & 3 & 2 & 0 & 0 & 0 & 0 & 0 & 0 & 0 & 0 \\
\hline 3 & 8.5 & 8.5 & 8.5 & 7.5 & 7 & 6.5 & 5.5 & 5 & 2.5 & 2 \\
\hline 4 & 0 & 0 & 0 & 0 & 0 & 0 & 0 & 0 & 0 & 0 \\
\hline 5 & 14 & 14 & 13.5 & 13.5 & 13 & 12.5 & 12 & 10.5 & 8 & 4 \\
\hline 6 & 5.5 & 4.5 & 4 & 1 & 0 & 0 & 0 & 0 & 0 & 0 \\
\hline 7 & 2 & 0 & 0 & 0 & 0 & 0 & 0 & 0 & 0 & 0 \\
\hline 8 & 6 & 5 & 1.5 & 0 & 0 & 0 & 0 & 0 & 0 & 0 \\
\hline 9 & 5.5 & 5.5 & 4.5 & 4.5 & 4.5 & 4.5 & 3.5 & 3 & 3 & 2 \\
\hline 10 & 8.5 & 8.5 & 8.5 & 8 & 7.5 & 7 & 6.5 & 5 & 0 & 0 \\
\hline 11 & 7 & 7 & 6 & 6 & 6 & 6 & 6 & 6 & 6 & 6 \\
\hline 12 & 12.5 & 12.5 & 12 & 11 & 11 & 11 & 11 & 11 & 7.5 & 5.5 \\
\hline$p$ & 0.018 & 0.006 & 0.005 & 0.002 & 0.001 & 0.001 & 0.000 & 0.001 & 0.006 & 0.009 \\
\hline$r^{b}$ & 0.665 & 0.741 & 0.749 & 0.787 & 0.810 & 0.810 & 0.862 & 0.838 & 0.737 & 0.711 \\
\hline
\end{tabular}

${ }^{\mathrm{a}}$ The cell values demonstrate the whole circumferential length of esophagus receiving a dose greater than a certain dose per fractionation. For example, "2.7Gy $13 \mathrm{~cm}$ " demonstrated that the whole circumferential length of esophagus received 2.7Gy per fraction or more was $13 \mathrm{~cm}$

bu" refers to the correlation coefficient calculated by Spearman's testing

$8.3 \%(1 / 12)$. There was no progressive disease (PD), and the total response rate (RR) was $91.7 \%(11 / 12)$.

\section{Survival}

Although this phase II trial was prematurely terminated, we still reported the preliminary survival results. Because the follow-up time was short (5-16 months), the median follow-up was 10 months, there were only two cases of death, and the survival information of OS was not mature. The median PFS, OS and LC, were not reached. The mean PFS, OS, and LC were 12.3, 14.3, and 12.9 months,

Table 7 Irradiation dose to esophagus: Maximum and mean

\begin{tabular}{lll}
\hline NO. & Maximum (Gy) & Mean (Gy) \\
\hline 1 & 2832 & 263 \\
2 & 5793 & 1183 \\
3 & 7023 & 2029 \\
4 & 2887 & 1063 \\
5 & 7203 & 3916 \\
6 & 5839 & 1181 \\
7 & 4510 & 766 \\
8 & 5045 & 2092 \\
9 & 6992 & 2025 \\
10 & 6892 & 2748 \\
11 & 7004 & 2304 \\
12 & 7222 & 4282 \\
$p$ & 0.010 & 0.004 \\
$r^{a}$ & 0.710 & 0.759 \\
\hline au $r$ " refers to the correlation coefficient calculated by Spearman's testing
\end{tabular}

respectively. The 1-year PFS, OS, and LC were $58.3 \%$, $78.6 \%$, and $64.2 \%$, respectively. There were four cases of treatment failure with two cases of simple local progression, one case of local progression plus distant metastasis (metastasis in both lung), and one case of simple distant metastasis (multiple ipsilateral lung metastasis). Regarding the cause of the two deaths, one case was due to local progression, and one case was due to local progression plus distant metastasis.

\section{Discussion}

The treatment failure of the primary lesions of NSCLC had negative effects on PFS, metastasis-free survival, and OS [37]. Increasing the tumor radiation dose could increase the local control and improve survival $[5,38]$. A study using model analysis obtained the same conclusion: the radiotherapy dose and survival had a significant dose-effect relationship, and a high radiotherapy dose could obtain a better 2-year PFS [8]. However, only increasing the radiotherapy dose alone was not sufficient. RTOG0617 used 74 Gy for conventional radiotherapy (concurrent with chemotherapy), and the total treatment time was as long as 7.4 weeks; the results showed that OS was not improved [7]. The other key factor for the radiotherapy efficacy was the total treatment time $[10,11]$. Shortening the total treatment time could increase the BED [11]. Application of the hypofractionated radiotherapy not only could obtain higher BED but also could shorten the total treatment time [36]. Therefore, compared with hyperfractionated radiotherapy, it might obtain more benefits [8]. 
Table 8 Hematologic toxicity

\begin{tabular}{|c|c|c|c|c|c|c|c|c|c|c|}
\hline \multirow[t]{2}{*}{ Item } & \multicolumn{2}{|c|}{ Grade I } & \multicolumn{2}{|c|}{ Grade II } & \multicolumn{2}{|c|}{ Grade III } & \multicolumn{2}{|c|}{ Grade IV } & \multicolumn{2}{|l|}{ Total } \\
\hline & Case & $\%$ & Case & $\%$ & Case & $\%$ & Case & $\%$ & Case & $\%$ \\
\hline Neutropenia & 1 & 8.3 & 3 & 25.0 & 1 & 8.3 & 1 & 8.3 & 6 & 50.0 \\
\hline Thrombocytopenia & 3 & 25.0 & 0 & 0 & 0 & 0 & 0 & 0 & 3 & 25.0 \\
\hline Anemia & 2 & 16.7 & 0 & 0 & 0 & 0 & 0 & 0 & 2 & 16.7 \\
\hline
\end{tabular}

Many studies have reported implementing hypofractionated radiotherapy on unresectable early- and middlestage NSCLC (IA-IIB); the results showed that there was no severe esophagus and lung toxicities, and the survival results were inspiring [12-15]. Hypofractionated radiotherapy (with or without sequential chemotherapy) on locally advanced NSCLC was also safe and effective. Concerning the toxicity of hypofractionated radiotherapy, the single fractionated dose was rarely above $3 \mathrm{~Gy} /$ fraction [16-21]. Radiotherapy with 55 Gy/20 fraction and $2.75 \mathrm{~Gy} /$ fraction was extensively applied in the UK. Din et al. [39] retrospectively analyzed 609 cases of hypofractionated radiotherapy, and the results showed that there were 227 cases of IIIA/IIIB, the MST was 20 months, the 2-year OS was $40 \%$, and toxicity could be tolerated. This regimen could also be implemented safely in the elderly population over the age of 80 years [18].

Conventional fractionated radiotherapy with concurrent chemotherapy was better than simple radiotherapy or sequential radiochemotherapy $[3,4]$. Theoretically, it was hypothesized that hypofractionated radiotherapy with concurrent chemotherapy could reasonably further increase efficacy. Therefore, studies exploring hypofractionated radiotherapy with concurrent chemotherapy are emerging [22-29]. These studies obtained inspiring survival results: the MST was 13.4-29.5 months, the 1-year OS was 56-90 \%, and the 2-year OS was 30-58.3\% [24-29]. However, except for two studies [24, 27], all other studies had a small sample size and were singlegroup and phase I/II trials; the number of cases was small with only 10-37 participants. Therefore, these survival results must be confirmed by phase III randomized controlled trials. Although the multivariate analysis in a non-randomized retrospective study showed that radiochemotherapy was the only survival predictive factor [40], but two prospective studies did not confirm that concurrent radiochemotherapy was better than sequential radiochemotherapy [24, 27]. EORTC 08912-22973 was a randomized controlled trial with the most cases; it enrolled 158 patients and used the radiotherapy regimen of $66 \mathrm{~Gy} / 24$ fractions and $2.75 \mathrm{~Gy} /$ fraction. The concurrent chemotherapy used a low dose of cisplatin at $6 \mathrm{mg} / \mathrm{m}^{2}$ every day. The MST, 2-year OS, and 3-year OS in the concurrent radiochemotherapy group and sequential radiochemotherapy group were 16.5 months and 16.2 months, $39 \%$ and $34 \%$, and $34 \%$ and $22 \%$, respectively; there were no significant differences [27]. The Sequential or Concurrent Chemotherapy and Radiotherapy (SOCCAR) trial enrolled 130 cases. The radiotherapy regimen was $55 \mathrm{~Gy} / 20$ fractions and $2.75 \mathrm{~Gy} /$ fraction. The chemotherapy was the vinorelbine + cisplatin regimen. Although both groups obtained good survival results, there was no significant difference. The MST, 1-year OS, and 2-year OS in these two groups were 24.3 months and 18.4 months, $70 \%$ and $83 \%$, and $50 \%$ and $46 \%$, respectively [24]. The hypofractionated regimens used in the above studies had very large differences; the fractionated dose ranged from $2.4 \mathrm{~Gy} /$ fraction to $3.5 \mathrm{~Gy} /$ fraction, the total dose ranged from 52.5 Gy to $66 \mathrm{~Gy}$, and the total treatment time ranged from 26 days to 37 days, and the results were different; therefore, it was difficult to choose the best regimen from these results.

Our previous study performed dose escalation of the 3Gy/fraction radiotherapy. The maximum-tolerated dose (MTD) recommended in the phase II trial was $69 \mathrm{~Gy} / 23$ fractions [32]. However, currently, our phase II trial only enrolled 12 cases. Due to the aggressive esophageal toxicity (mainly esophageal pain) and lung toxicity, the trial was prematurely terminated. The percentage of grade III acute esophagitis in our study was far higher than those in other hypofractionated reports and reached $41.7 \%(5 / 12)$. Five cases presented with intolerable esophageal pain, and $80 \%(4 / 5)$ had different degrees of dysphagia, of which one case had very severe dysphagia and could only drink a small amount of water. It was considered that the reasons for the development of such severe esophagitis might be associated with the following factors. First, the total dose was $69 \mathrm{~Gy}$, and the fractionated dose was $3 \mathrm{~Gy} /$ fraction in our radiotherapy regimen. The radiation on the esophagus regardless of the total dose or single dose might both be very high [41, 42]. In addition, since the single fractionated dose was large, the rapidity of dose accumulation on the esophagus might cause severe esophagitis [36]. Second, the whole group had $41.7 \%$ lymph node metastasis with more than four stations and $50 \%$ N3 lesions, thus causing extensive involvement of the mediastinum. Mediastinal infiltration and extensive lymph node metastasis are factors for the high incidence of esophagitis [16]. Third, $41.7 \%$ patients had Station 7 metastasis. Station 7 was adjacent to the esophagus; therefore, it was easy to cause the highdose radiation on esophagus. In our study, the occurrence of esophagitis was early; the earliest case (No. 5) had 
already developed the complication at the $10^{\text {th }}$ fraction. Although the corresponding measures such as narcotic analgesic drug administration and nutrition support were provided, the grade III esophagitis persisted for 23 days before being reduced to grade II, thus causing 16 days of radiotherapy interruption. This patient had eight stations of mediastinal lymph node metastasis-1R, $2 \mathrm{R}, 4 \mathrm{R}, 4 \mathrm{~L}, 5$, 7,8 , and 10 . The V60 reached $49.9 \%$. The whole circumferential length of esophagus receiving more than $2.7 \mathrm{~Gy}$ and 3 Gy per fraction reached $13 \mathrm{~cm}$ and $4 \mathrm{~cm}$, respectively. Regardless of the total radiation dose, irradiation length, dose-volume percentage, or irradiation dose per fraction to esophagus, they were all very high.

The dosimetric parameters of the occurrence of radiation esophagitis might be associated with the maximum radiation dose, irradiation length, and dose-volume parameters of the esophagus [41-45]. Our study also confirmed these results. However, there were also some conflicting studies considering that these parameters did not have a clear correlation with esophagitis [46, 47]. The dosimetric parameters of radiation esophagitis could not draw a very firm conclusion [36], particularly for hypofractionated radiotherapy with concurrent chemotherapy [22].

When the five cases of grade III esophagitis occurred in our study, the completed radiation dose was only $43 \%$, $52 \%, 57 \%, 57 \%$, and $65 \%$ of the plan. In addition, at the end, they did not complete the radiation of the total dose (with the exception of the patient who had a 16-day interruption). Therefore, the maximum radiation dose and dose-volume parameters of the esophagus in these patients might not be the most relevant factors to predict severe esophagitis [36]. Studies have shown that severe esophagitis was closely associated with the rapid accumulation of the radiation dose of the esophagus, a finding that might be more important than the final completed total irradiation dose [36]. A single large-dose radiation on the esophagus would induce the rapid increase of the radiation dose of the esophagus. Our study also observed this condition: the percentage of severe esophagitis in patients who received one single dose per fraction of $\geq 2.7$-Gy radiation on the esophagus was markedly higher than in those who received a dose lower than 2.7 Gy ( $80 \%$ vs 0 , respectively). Although there was no significant difference, it was considered that the cause might be due to the very small sample size. Therefore, we considered that the severe acute radiation esophagitis might be closely associated with the irradiation dose per fraction to esophagus $\geq 2.7 \mathrm{~Gy}$.

Other hypofractionated radiotherapy studies also exhibited similar phenomena [26, 27]. Koukourakis et al. applied the $3.5 \mathrm{~Gy} /$ fraction concurrent radiochemotherapy, although there was a routine 9-day interval, and also applied the cytoprotective adjuvant amifostine; however, the grade III esophagitis still reached $22.5 \%$ [26]. A study that applied $2.75 \mathrm{~Gy} /$ fraction had $17 \%$ grade III/IV esophagitis [27]. In these two high single-dose hypofractionated studies, the percentages of esophagitis were significantly higher than those in hypofractionated studies using a relatively smaller single dose $[25,28,29]$. EORTC 08912 [23] applied a large fractionated dose of $2.75 \mathrm{~Gy} /$ fraction; 17 cases received a total radiation dose $>60$ Gy of the esophagus that was one single irradiation dose of $>2.5 \mathrm{~Gy} /$ fraction, and the mean length reached $11.4 \mathrm{~cm}$. However, there were only two cases of grade III esophagitis; the radiation doses of the esophagus of these two cases were $65 \mathrm{~Gy}$ and $66 \mathrm{~Gy}$, respectively-that is, the single irradiation doses were $2.71 \mathrm{~Gy}$ and $2.75 \mathrm{~Gy}$, respectively. These results were consistent with our study results suggesting that the single dose equal to or larger than 2.7 Gy would induce severe esophagitis. Research in the Netherlands reported two cases of grade IV esophageal toxicity of which the radiation dose of the esophagus in one case was $66 \mathrm{~Gy} / 27$ fraction and $2.75 \mathrm{~Gy} /$ fraction [40]. The above analyses supported the following conclusion. A single dose radiation per fraction $\geq 2.7$ Gy in hypofractionated radiotherapy with concurrent chemotherapy might induce severe radiation esophagitis. In the three studies applying relatively small fractionated doses (2.5 Gy, 2.4 Gy, and 2.4 Gy, respectively), two studies did not have grade III or higher esophagitis [25, 29], and the other one only had $3 \%$ of grade III esophagitis [28]. However, the number of cases in these studies was small, and the number of severe esophagitis cases was even smaller; therefore, this phenomenon was not a confirmed conclusion. In our study, among the five cases of grade III acute esophagitis, only one case was finally transformed into late grade III esophageal injury, indicating that 69 Gy might not cause a severe late esophageal toxicity. However, this result should be treated cautiously because only one case among these five cases completed $69 \mathrm{~Gy}$ of radiation (the radiotherapy was interrupted for 16 days due to esophagitis). This case showed rapid disease progression and died after 4 months of completion of the radiotherapy; the observation time was short and was not sufficient to exclude the possibility of the occurrence of grade III and above late esophageal injury. Three of other four cases completed only 74-78 \% of the radiation dose; therefore, it could not verify the safety of the 69 Gy of radiation.

In our study, two cases of grade III radiation pneumonitis (16.7 \%) transformed into one case of late grade III lung injury and one case of late grade II lung injury after 90 days. It was worth noting that patients who completed 69 Gy of radiation according to the plan had $28.6 \%$ grade III radiation pneumonitis (2/7), and the actual incidence of lung injury might be underestimated (one case died due to disease progression after 4 months of the completion of radiotherapy; thus, the evaluation time for lung injury was short). Currently, there are no established data to guide the prevention and reduction 
of the development of radiation pneumonia during hypofractionated radiotherapy. Studies have shown that application of hypofractionated radiotherapy using the dose parameters obtained mainly from conventional hypofractionated radiotherapy might induce severe lung toxicity $[48,49]$. Therefore, the possibility of developing severe radiation pneumonia during hypofractionated radiotherapy is highly vigilant.

In our study, at the median 10-month follow-up, as high as $41.7 \%$ grade III acute esophagitis and $28.6 \%$ grade III acute pneumonitis (patients who completed the radiotherapy plan) were already observed. The late lung toxicity might be underestimated because of short follow-up time [48]. Because a late lung toxicity was usually fatal $[48,49]$, we considered that this hypofractionated radiochemotherapy regimen was not safe. In addition, grade III esophagitis in this study presented prominently esophageal pain; thus, $33.3 \%$ patients in this group could not complete the whole $69-$ Gy radiotherapy, and the compliance of this regimen was poor. Therefore, this phase II trial was terminated early.

In our phase I study, the 69-Gy group enrolled six patients. There were only two cases of grade II esophagitis, and there was no grade III and above esophagitis. The esophageal toxicity was significantly lower than that in the current study [32]. We reviewed the dosimetric parameters of the six patients and found that the maximum total doses of the esophagus of all patients were all $\leq 55.2 \mathrm{~Gy}$-that is, the maximum single dose per fraction of radiation was $\leq 2.4$ Gy. In the phase II study, the maximum irradiation dose per fraction to esophagus of four patients was $\leq 2.4 \mathrm{~Gy}$, and there was no grade III esophagitis, findings that were consistent with the result of the hypofractionated concurrent radiochemotherapy using a relatively small single dose $[25,28,29]$. In our phase I study, the 69-Gy group did not have grade III radiation pneumonitis. The latter finding was considered to be associated with the selection bias caused by the small number of cases. A similar phenomenon was also observed in a Canadian report. The maximum single dose per fraction of the dose-escalation was 3.24 Gy/ fraction, the total dose was $70.7 \mathrm{~Gy}$, the concurrent fulldose etoposide/cisplatin (EP) chemotherapy regimen was conducted for 2 cycles, and the median 22-month follow-up showed no grade III and above toxicity. Because there were only 10 patients in the group, the authors considered that the results should be cautiously treated with optimism because of the small sample size [25]. Therefore, if the case number in the dose-escalation group was small, the result was not sufficient to exhibit the safety of this dose level, particularly with high-dose hypofractionated radiation [48]. The survival data in our study are still not mature, and the MST was not achieved; however, for the 1-year OS of $78.6 \%$, these results were comparable to those of other literature reports (OS from $56 \%$ to $90 \%$ ) [24-29].

The studies on conventional fractionated radiotherapy in NSCLC focused heavily on lung toxicity However, they did not focus on the protection of the esophagus, and some studies did not even have limitation of irradiation dose to esophagus $[28,29,50]$. Currently, the predictive factors and dose-volume parameters for esophagitis still cannot provide a confirmed conclusion, and the hypofractionated radiotherapy even requires new dosimetric parameters and other factors for evaluation [36]. Although esophagitis, particularly acute esophagitis, is not fatal, it might affect the completion of the radiotherapy plan, interrupt radiotherapy, or decrease the radiation dose, thus reducing the local control rate. This situation is even more prominent in hypofractionated radiotherapy. Some studies have considered that the major obstacle of doseescalation in hypofractionated radiotherapy was caused by the esophagus [37, 40, 48], a finding that was also confirmed in our phase II study. Therefore, during hypofractionated radiotherapy, particularly concurrent radiochemotherapy, in addition to lung toxicity, acute esophageal toxicity should also be given close attention. The toxicity analysis in hypofractionated concurrent radiochemotherapy showed that the traditional dosimetric parameters did not have a good correlation with esophagitis [22]. Therefore, exploring new predictive factors for esophagitis, particularly for late esophageal injury, has very important clinical significance.

Most radiotherapy studies used the unified prescription dose. However, the application of a fixed dose to all patients might have two consequences. First, some patients might receive a very low radiotherapy dose with insufficient treatment intensity, while other patients might receive a very high radiotherapy dose with strong side effects. The so-called "in silico" dose prescription refers to the radiation dose limitation of normal tissues being set up in advance and is used as a standard to allow each patient to receive individualized different maximum radiation doses without increasing toxicity; thus, the treatment intensity is sufficient and safe; this dose is also called the "isotoxic" prescription dose [37, 50-52]. In hyperfractionated studies, the application of this method effectively allows escalation of the radiotherapy dose; in addition, the mature survival results showed that the MST at the IIIB phase reached 17.2 months. This series of studies only conducted limitations of radiation dose on the lung and spinal cord [50-52]. Hoffmann et al. [37] applied the in silico method to perform a study on individualized dose prescription for hypofractionation and pre-set the limits of radiation dose on the esophagus, lung, spinal cord, heart, and brachial plexus. The results of the model analysis showed that $79 \%$ of cases had a therapeutic gain in dose 
escalation. During the pre-set of the radiation dose for normal tissues, the "physical dose" was transformed into the "biological effective dose"; thus, it was more in line with the radiation injury reaction of normal tissues after radiation and might be beneficial for reducing toxicity $[16,25]$.

Modern advance radiotherapy technologies, including intensity-modulated radiation therapy (IMRT), imageguided radiation therapy (IGRT), 4D-CT, breathing adapted radiotherapy, particle radiotherapy [53], and tomotherapy [54], can more accurately irradiate tumors; at the same time, the radiation dose of surrounding normal tissues can be reduced. Using the in silico method combined with advanced radiotherapy technology to perform radiotherapy with an individualized maximum dose based on the isotoxicity of normal tissues can theoretically achieve the dose-escalated hypofractionated concurrent radiochemotherapy more safely.

\section{Conclusion}

In summary, although our hypofractionated concurrent chemoradiotherapy regimen (69 Gy/23 fractions, 3 Gy/ fraction) showed preliminary efficacy, it resulted in aggressive esophagus and lung toxicity; particularly, severe esophagitis significantly affected the completion of radiotherapy. Therefore, this regimen was not feasible. Although, it was not the final conclusion, our study suggested that an irradiation dose per fraction to esophagus during hypofractionated concurrent radiochemotherapy should be controlled to be below 2.7 Gy. Currently, we are performing radiation dose escalation in hypofractionated radiochemotherapy of NSCLC using the in silico method according to different irradiation doses per fraction to the esophagus.

\section{Ethics approval and consent to participate}

This trial was performed in accordance with the principles of human clinical trials and the Helsinki Declaration (1975 edition and 2000 revised edition). This trial was approved by the Ethics Committee of the North China Petroleum Bureau General Hospital of Hebei Medical University.

All participants signed informed consent before enrollment.

\section{Abbreviations}

3D-CRT: Three-dimensional conformal radiation therapy; CR: Complete response; hypoRT: Hypofractionated radiation therapy; KPS: Karnofsky performance status; NC: Vinorelbine and carboplatin; NSCLC: Non-small cell lung cancer; PD: Progressive disease; PR: Partial response; SD: Stable disease; TP: Paclitaxel and cisplatin.

\section{Authors' contributions}

XR participated in the design of the subject, analyzed data and draft the manuscript. QW participated in the design of the subject, analyzed data and carried out the clinical implementation of the study. RZ participated in the design of the subject and carried out the clinical implementation of the study. XC carried out the clinical implementation of the study and acquired data. NW carried out the clinical implementation of the study and acquired data. YL carried out the clinical implementation of the study and acquired data. JZ carried out the clinical implementation of the study and acquired data. ZG participated in the design of the subject and interpreted data. DW guided the design of the subject and helped to draft the manuscript. QL (the corresponding author) was the PI of this clinical trial, who designed the subject and helped to draft the manuscript. All authors read and approved the final manuscript.

\section{Authors' information}

$\mathrm{QL}$, the corresponding author, is the Associate Professor of Department of Oncology, North China Petroleum Bureau General Hospital of Hebei Medical University, 8 Huizhan Avenue, Renqiu City, Hebei Province, and P.R. China. He is focusing on the chemoradiotherapy on the thoracic neoplasm. He has found difference tolerance between Asian patients and Western patients when they received concurrent chemoradiotherapy in lung cancer and esophageal carcinoma.

\section{Acknowledgements}

None

\section{Funding}

This work was supported partly by the Science and Technology Department of Hebei Province, People's Republic of China (No. 072761711).

\section{Author details}

${ }^{1}$ Department of Oncology, North China Petroleum Bureau General Hospital of Hebei Medical University, 8 Huizhan Avenue, Renqiu City, Hebei Province 062552, P.R. China. '2Department of Radiology, North China Petroleum Bureau General Hospital of Hebei Medical University, 8 Huizhan Avenue, Renqiu, Hebei Province 062552, P.R. China. ${ }^{3}$ Department of Cardiovascular Medicine, North China Petroleum Bureau General Hospital of Hebei Medical University, 8 Huizhan Avenue, Renqiu, Hebei Province 062552, P.R. China.

Received: 3 March 2015 Accepted: 13 April 2016

Published online: 23 April 2016

\section{References}

1. Ferlay J, Shin HR, Bray F, Forman D, Mathers C, Parkin DM. Estimates of worldwide burden of cancer in 2008. Int J Cancer. 2010;127:2893-917.

2. Chen W, Zheng R, Zhang S, Zhao P, Hongmei Z, Zou X. Report of cancer incidence and mortality in China, 2010. Annals of Trans Med. 2014;2:61.

3. Bayman N, Blackhall F, McCloskey P, Taylor P, Faivre-Finn C. How can we optimise concurrent chemoradiotherapy for inoperable stage III non-small cell lung cancer? Lung Cancer. 2014;83:117-25.

4. Aupérin A, Le Péchoux C, Rolland E, Curran WJ, Furuse K, Fournel P, et al. Meta-analysis of concomitant versus sequential radiochemotherapy in locally advanced non-small-cell lung cancer. J Clin Oncol. 2010;28:2181-90.

5. Kong FM, Ten Haken RK, Schipper MJ, Sullivan MA, Chen M, Lopez C, et al. High-dose radiation improved local tumor control and overall survival in patients with inoperable/unresectable non-small-cell lung cancer: Longterm results of a radiation dose escalation study. Int J Radiat Oncol Biol Phys. 2005:63:324-33.

6. Machtay M, Bae K, Movsas B, Paulus R, Gore EM, Komaki R, et al. Higher biologically effective dose of radiotherapy is associated with improved outcomes for locally advanced non-small cell lung carcinoma treated with chemoradiation: an analysis of the Radiation Therapy Oncology Group. Int J Radiat Oncol Biol Phys. 2012;82:425-34

7. Bradley JD, Paulus R, Komaki R, Masters G, Blumenschein G, Schild S, et al. Standard-dose versus high-dose conformal radiotherapy with concurrent and consolidation carboplatin plus paclitaxel with or without cetuximab for patients with stage IIIA or IIIB non-small-cell lung cancer (RTOG 0617): a randomised, two-by-two factorial phase 3 study. Lancet Oncol. 2015;16:187-99.

8. Withers HR, Taylor JM, Maciejewski B. The hazard of accelerated tumor clonogen repopulation during radiotherapy. Acta Oncol. 1988;27:131-46. 
9. Koukourakis M, Hlouverakis G, Kosma L, Skarlatos J, Damilakis J, Giatromanolaki A, et al. The impact of overall treatment time on the results of radiotherapy for nonsmall cell lung carcinoma. Int J Radiat Oncol Biol Phys. 1996:34:315-22.

10. Saunders M, Dische S, Barrett A, Harvey A, Griffiths G, Parmar M. Continuous, hyper-fractionated, accelerated radiotherapy (CHART) versus conventional radiotherapy in non-small cell lung cancer: mature data from the randomized multicentre trial. CHART Steering committee. Radiother Oncol. 1999:52:137-48

11. Beli I, Koukourakis G, Platoni K, Tolia M, Kelekis N, Kouvaris J, et al. Hypofractionated radiotherapy in non small cell lung cancer: a review of the current literature. Rev Recent Clin Trials. 2010;5:103-11.

12. Lester JF, Macbeth FR, Brewster AE, Court JB, lqbal N. CT-planned accelerated hypofractionated radiotherapy in the radical treatment of nonsmall cell lung cancer. Lung Cancer. 2004;45:237-42.

13. Oh D, Ahn YC, Kim B, Pyo H. Hypofractionated three-dimensional conformal radiation therapy alone for centrally located cT1-3 N0 non-small-cell lung cancer. J Thorac Oncol. 2013;8:624-9.

14. Cheung P, Faria S, Ahmed S, Chabot P, Greenland J, Kurien E, et al. Phase II study of accelerated hypofractionated three-dimensional conformal radiotherapy for stage T1-3 N0 M0 non-small cell lung cancer: NCIC CTG BR. J Natl Cancer Inst. 2014;106:8.

15. Souhami L, Portelance L, Duclos M, Vuong T, Small D, Freeman CR. Absence of toxicity with hypofractionated 3-dimensional radiation therapy for inoperable, early stage non-small cell lung cancer. Radiat Oncol. 2006;1:42.

16. Gomez DR, Gillin M, Liao Z, Wei C, Lin SH, Swanick C, et al. Phase 1 study of dose escalation in hypofractionated proton beam therapy for non-small cell lung cancer. Int J Radiat Oncol Biol Phys. 2013;86:665-70.

17. Amini A, Lin SH, Wei C, Allen P, Cox JD, Komaki R. Accelerated hypofractionated radiation therapy compared to conventionally fractionated radiation therapy for the treatment of inoperable non-small cell lung cancer. Radiat Oncol. 2012;7:33.

18. McPartlin AJ, Chaudhry S, Swindell R, Bayman N, Burt P, Chittalia A, et al. The largest UK single centre series using hypofractionated radical radiotherapy for NSCLC in the very elderly. Lung Cancer. 2013;81:144.

19. Thirion $\mathrm{P}$, Holmberg $O$, Collins CD, O'Shea C, Moriarty M, Pomeroy M, et al. Escalated dose for non-small-cell lung cancer with accelerated hypofractionated three-dimensional conformal radiation therapy. Radiother Oncol. 2004;71:163-6.

20. Duchateau M, Versmessen H, Engels B, Tournel K, Vinh-Hung V, De Ridder $M$, et al. Toxicity and outcome results of a class solution with moderately hypofractionated radiotherapy in inoperable Stage III non-small cell lung cancer using helical tomotherapy. Int J Radiat Oncol Biol Phys. 2010;77:1352-9.

21. Kepka L, Tyc-Szczepaniak D, Bujko K. Dose-per-fraction escalation of accelerated hypofractionated three-dimensional conformal radiotherapy in locally advanced non-small cell lung cancer. J Thorac Oncol. 2009:4:853-61.

22. Tho LM, Mahmood R, Leitch M, Brisbane I, Kakumanu S, Mohammed N. Oesophageal toxicity and hypofractionated concurrent chemoradiotherapy for non-small cell lung cancer. Clin Oncol (R Coll Radiol). 2009;21(1):74.

23. Uitterhoeve AL, Belderbos JS, Koolen MG, van der Vaart PJ, Rodrigus PT, Benraadt J, et al. Toxicity of high-dose radiotherapy combined with daily cisplatin in non-small cell lung cancer: results of the EORTC 08912 phase I/II study. European Organization for Research and Treatment of Cancer. Eur J Cancer. 2000;36:592-600

24. Maguire J, Khan I, McMenemin R, O'Rourke N, McNee S, Kelly V, et al. SOCCAR: A randomised phase II trial comparing sequential versus concurrent chemotherapy and radical hypofractionated radiotherapy in patients with inoperable stage III Non-Small Cell Lung Cancer and good performance status. Eur J Cancer. 2014;50:2939-49.

25. Kim JO, Chu KP, Fairchild A, Ghosh S, Butts C, Chu Q, et al. Dose-escalated Hypofractionated Intensity-modulated Radiation Therapy With Concurrent Chemotherapy for Inoperable or Unresectable Non-Small Cell Lung Cancer. Am J Clin Oncol. 2014. doi:10.1097/COC.0000000000000140 [Epub ahead of print].

26. Koukourakis M, Patlakas G, Froudarakis ME, Kyrgias G, Skarlatos J, Abatzoglou I, et al. Hypofractionated accelerated radiochemotherapy with cytoprotection (Chemo-HypoARC) for inoperable non-small cell lung carcinoma. Anticancer Res. 2007;27:3625-31.

27. Belderbos J, Uitterhoeve L, van Zandwijk N, Belderbos H, Rodrigus P, Van de Vaart $P$, et al. Randomised trial of sequential versus concurrent chemoradiotherapy in patients with inoperable non-small cell lung cancer (EORTC 08972-22973). Eur J Cancer. 2007;43:114-21.
28. Alessandra B, Emilio M, Imad Abu R, Eugenio B, Renato T, Giovanni F, et al. Concurrent chemoradiotherapy with tomotherapy in locally advanced nonsmall cell lung cancer: a phase i, docetaxel dose-escalation study, with hypofractionated radiation regimen. BMC Cancer. 2013;13:513.

29. Matsuura K, Kimura T, Kashiwado K, Fujita K, Akagi Y, Yuki S, et al. Results of a preliminary study using hypofractionated involved-field radiation therapy and concurrent carboplatin/paclitaxel in the treatment of locally advanced non-small-cell lung cancer. Int J Clin Oncol. 2009;14:408-15.

30. Dillman RO, Herndon J, Seagren SL, Eaton Jr WL, Green MR. Improved survival in stage III non-small-cell lung cancer: seven year follow-up of cancer and leukemia group B (CALGB) 8433 trial. J Natl Cancer Inst. 1996;88: 1210-5.

31. Ohri N, Dicker AP, Lawrence YR. Can drugs enhance hypofractionated radiotherapy? A novel method of modeling radiosensitization using in vitro data. Int J Radiat Oncol Biol Phys. 2012;83:385-93.

32. Lin Q, Liu YE, Ren XC, Wang N, Chen XJ, Wang DY, et al. Dose escalation of accelerated hypofractionated three-dimensional conformal radiotherapy (at 3 Gy/fraction) with concurrent vinorelbine and carboplatin chemotherapy in unresectable stage III non-small-cell lung cancer: a phase I trial. Radiat Oncol. 2013:8:201

33. Zhu ZF, Fan $M$, Wu KL, Zhao KL, Yang HJ, Chen GY, et al. A phase II trial of accelerated hypofractionated three-dimensional conformal radiation therapy in locally advanced nonsmall cell lung cancer. Radiother Oncol. 2011;98: 304-8.

34. Eisenhauer EA, Therasse P, Bogaerts J, Schwartz LH, Sargent D, Ford R, et al. New response evaluation criteria in solid tumours: revised RECIST guideline (version 1.1). Eur J Cancer. 2009;45:228-47.

35. Colevas $\mathrm{AD}$, Setser $\mathrm{A}$, The $\mathrm{NCl}$. Common terminology criteria for adverse events (CTCAE) $\vee 3.0$ is the new standard for oncology clinical trials. J Clin Oncol. 2004;22 Suppl 14:6098.

36. Werner-Wasik M, Yorke E, Deasy J, Nam J, Marks LB. Radiation dose-volume effects in the esophagus. Int J Radiat Oncol Biol Phys. 2010;76:S86-93.

37. Hoffmann AL, Troost EG, Huizenga H, Kaanders JH, Bussink J. Individualized dose prescription for hypofractionation in advanced non-small-cell lung cancer radiotherapy: an in silico trial. Int J Radiat Oncol Biol Phys. 2012;83: 1596-602.

38. Adkison JB, Khuntia D, Bentzen SM, Cannon GM, Tome WA, Jaradat $H$, et al. Dose escalated, hypofractionated radiotherapy using helical tomotherapy for inoperable non-small cell lung cancer: preliminary results of a risk-stratified phase I dose escalation study. Technol Cancer Res Treat. 2008;7:441-7.

39. Din OS, Harden SV, Hudson E, Mohammed N, Pemberton LS, Lester JF, et al. Accelerated hypo-fractionated radiotherapy for non small cell lung cancer: results from 4 UK centres. Radiother Oncol. 2013;109(1):8-12.

40. Cornelissen R, Senan S, Antonisse IE, Liem H, Tan YK, Rudolphus A, et al. Bronchiolitis obliterans organizing pneumonia (BOOP) after thoracic radiotherapy for breast carcinoma. Radiat Oncol. 2007;2:2.

41. Belderbos J, Heemsbergen W, Hoogeman M, Pengel K, Rossi M, Lebesque J. Acute esophageal toxicity in non-small cell lung cancer patients after high dose conformal radiotherapy. Radiother Oncol. 2005;75:157-64.

42. Singh AK, Lockett MA, Bradley JD. Predictors of radiation induced esophageal toxicity in patients with non small-cell lung cancer treated with three-dimensional conformal radiotherapy. Int J Radiat Oncol Biol Phys. 2003:55:337-41.

43. Rosenman JG, Halle JS, Socinski MA, Deschesne K, Moore DT, Johnson H, et al. High-dose conformal radiotherapy for treatment of stage IIIA/IIIB nonsmall-cell lung cancer: technical issues and results of a phase I/II trial. Int J Radiat Oncol Biol Phys. 2002;54:348-56.

44. Zhang Z, Xu J, Zhou T, Yi Y, Li H, Sun H, et al. Risk factors of radiationinduced acute esophagitis in non-small cell lung cancer patients treated with concomitant chemoradiotherapy. Radiat Oncol. 2014;9:54.

45. Maráz A, Furák J, Varga Z, Fodor E, Együd Z, Borzási E, et al. Acute oesophageal toxicity related to paclitaxel-based concurrent chemoradiotherapy for nonsmall cell lung cancer. Anticancer Res. 2013;33:1737-41.

46. Werner-Wasik M, Pequignot E, Leeper D, Hauck W, Curran W. Predictors of severe esophagitis include use of concurrent chemotherapy, but not the length of irradiated esophagus: a multivariate analysis of patients with lung cancer treated with nonoperative therapy. Int J Radiat Oncol Biol Phys. 2000:48:689-96

47. Maguire PD, Sibley GS, Zhou SM, Jamieson TA, Light KL, Antoine PA, et al. Clinical and dosimetric predictors of radiation-induced esophageal toxicity. Int J Radiat Oncol Biol Phys. 1999;45:97-103. 
48. Cannon DM, Mehta MP, Adkison JB, Khuntia D, Traynor AM, Tomé WA, et al. Dose-limiting toxicity after hypofractionated dose-escalated radiotherapy in non-small-cell lung cancer. J Clin Oncol. 2013;31:4343-8.

49. Machtay M, Washam C, Devine P. Pilot study of accelerated radiotherapy with concurrent chemotherapy for stage III non-small cell lung cancer. Semin Oncol. 2005;32 Suppl 3:S9-12.

50. van Baardwijk A, Bosmans G, Boersma L, Wanders S, Dekker A, Dingemans $\mathrm{AM}$, et al. Individualized radical radiotherapy of non-small-cell lung cancer based on normal tissue dose constraints: a feasibility study. Int J Radiat Oncol Biol Phys. 2008;71:1394-401.

51. van Baardwijk A, Bosmans G, Bentzen SM, Boersma L, Dekker A, Wanders R, et al. Radiation dose prescription for non-small-cell lung cancer according to normal tissue dose constraints: an in silico clinical trial. Int J Radiat Oncol Biol Phys. 2008;71:1103-10.

52. van Baardwijk A, Wanders S, Boersma L, Borger J, Ollers M, Dingemans AM, et al. Mature results of an individualized radiation dose prescription study based on normal tissue constraints in stages I to III non-small-cell lung cancer. J Clin Oncol. 2010;28:1380-6.

53. van Meerbeeck JP, Meersschout S, De Pauw R, Madani I, De Neve W. Modern radiotherapy as part of combined modality treatment in locally advanced non-small cell lung cancer: present status and future prospects. Oncologist. 2008;13:700-8.

54. Scrimger RA, Tomé WA, Olivera GH, Reckwerdt PJ, Mehta MP, Fowler JF. Reduction in radiation dose to lung and other normal tissues using helical tomotherapy to treat lung cancer, in comparison to conventional field arrangements. Am J Clin Oncol. 2003;26:70-8.

\section{Submit your next manuscript to BioMed Central and we will help you at every step:}

- We accept pre-submission inquiries

- Our selector tool helps you to find the most relevant journal

- We provide round the clock customer support

- Convenient online submission

- Thorough peer review

- Inclusion in PubMed and all major indexing services

- Maximum visibility for your research

Submit your manuscript at www.biomedcentral.com/submit

C Biomed Central 